\title{
Influence of ALD Coating Layers on the Optical Properties of Nanoporous Alumina-Based Structures
}

\author{
Ana L. Cuevas ${ }^{1}$, María del Valle Martínez de Yuso ${ }^{2}$, Víctor Vega ${ }^{3}$, Ana Silvia González ${ }^{4}$, \\ Víctor M. Prida ${ }^{4}\left(\mathbb{D}\right.$ and Juana Benavente ${ }^{5, *}$ \\ 1 Unidad de Nanotecnología, SCBI Centro, Universidad de Málaga, E-29071 Málaga, Spain; \\ analaura.cuevas@uma.es \\ 2 Servicios Centrales de Investigación, Universidad de Málaga, E-29071 Málaga, Spain; mvyuso@uma.es \\ 3 Laboratorio de Membranas Nanoporosas, Servicios Científico-Técnicos, Universidad de Oviedo, \\ E-33006 Oviedo, Spain; vegavictor@uniovi.es \\ 4 Departmento de Física, Facultad de Ciencias, Universidad de Oviedo, E-33007 Oviedo, Spain; \\ gonzalezgana@uniovi.es (A.S.G.); vmpp@uniovi.es (V.M.P.) \\ 5 Departmento de Física Aplicada I, Facultad de Ciencias, Universidad de Málaga, E-29071 Málaga, Spain \\ * Correspondence: j_benavente@uma.es; Tel.: +34-952-131-929
}

Received: 5 December 2018; Accepted: 11 January 2019; Published: 15 January 2019

\begin{abstract}
Optical changes associated with the surface coating of different metal oxides and nanolayers by the ALD technique of a nanoporous alumina structure (NPAS) obtained by the two-step anodization method were analyzed. The NPASs were coated with: (i) a single layer $\left(\mathrm{SiO}_{2}\right.$ or $\left.\mathrm{TiO}_{2}\right)$, and (ii) a double layer of $\mathrm{SiO}_{2}$ plus $\mathrm{Al}_{2} \mathrm{O}_{3}$ or aluminum doped $\mathrm{ZnO}$ (AZO) to estimate the effect of surface layer coverage material, geometrical parameters (pore-size/porosity), and number of layers on light transmission/reflection. Chemical surface characterization of the different NPASs was carried out by analyzing XPS spectra, which allowed us to obtain an estimation of the coating layer homogeneity. Transmittance and spectroscopic ellipsometry measurements were analyzed in order to detect changes in characteristic optical parameters such as band gap, refractive index, and extinction coefficients associated with the material and the characteristics of the single or double coating layers.
\end{abstract}

Keywords: nanoporous anodic alumina structures; ALD coating; XPS; spectroscopic ellipsometry; transmittance

\section{Introduction}

In the last 20 years, a significant number of papers focused on exploring the application of nanoporous materials synthesized by electrochemical techniques such nanoporous anodic alumina structures (NPASs) or porous silicon structures for application in sensing devices have been published [1-3]. In particular, the NPASs prepared by the anodization of aluminum foil by the two-step method present had enhanced thermal and chemical resistance as well as tunable optical properties and also had good biocompatibility and a large specific surface area [4-8]. This latter characteristic, the high specific surface area to volume ratio, is of great interest to enhance optical signals when the NPASs are incorporated into sensor devices [9]. In addition, their self-organized nanoporous structure with straight pores and a small pore size dispersion make NPASs excellent platforms for relevant applications (chemical/biological sensors, drug delivery, nanofilters, energy ... ) and template synthesis methods [10-16]. Moreover, the optical characteristics of NPASs such as light transmittance, absorbance, or reflectivity can be tools of interest for selective chemical and biochemical applications [9]. 
On the other hand, external and internal (or pore-walls) surfaces of the NPASs can easily be modified by different techniques such as dip-coating, sol-gel, chemical vapor deposition, or atomic layer deposition to obtain nanoporous structures with the most adequate pore size, chemical surface functionalization, selective transport/rejection of ions, and molecules or optical characteristics for a specific application [17-19]. In particular, the surface coating of NPASs by the atomic layer deposition (ALD) technique enables its modification through a broad range of materials (metal oxides, nitrides or sulfides), and has been used to modify both the external and inner surfaces of the NPASs due to its penetration along the nanopores [20-22]. As a consequence of the coating layer, a reduction in the pore radius and porosity of these new nanoporous alumina-based structures (NPA-bSs) as well as its effect on the diffusive transport (permselectivity and ion diffusion coefficients, parameters of interest for the membranes and nanofluidic applications), have already been observed [18,21], but changes in these latter parameters also seem to depend on the surface material used for nanopore coverage. Moreover, changes in the optical parameters of the NPASs dependent on thickness, pore size, and pore area percentage (or porosity) have already been reported [23,24]. Consequently, ALD coatings might also modify other characteristic properties of the nanoporous alumina support.

In this work, we describe the change in the optical properties associated with the surface coating of a NPAS by the ALD technique with different metal oxides through a single layer $\left(\mathrm{SiO}_{2}\right.$ and $\left.\mathrm{TiO}_{2}\right)$ and double layer $\left(\mathrm{SiO}_{2}+\mathrm{Al}_{2} \mathrm{O}_{3}\right.$ and $\left.\mathrm{SiO}_{2}+\mathrm{AZO}\right)$ as a way to establish differences associated with the coating-layer material and layer number, independent of pore size and the porosity of the nanoporous alumina-based structures (NPA-bSs). In both cases, the supporting NPAS was obtained by the two-step aluminum mild anodization method using an oxalic acid solution [4]. Chemical surface modification of the NPA-bSs caused by the ALD treatments were analyzed by the x-ray photoelectron spectroscopy (XPS) technique, which provides information on the homogeneity and purity of the coated layer, while optical characterization was performed directly on NPA-bSs by transmittance and spectroscopic ellipsometry measurements. $\mathrm{SiO}_{2}$ and $\mathrm{TiO}_{2}$ were selected for alumina coverage due to the characteristics of these materials (chemical and thermal stability) as well as the biocompatibility of the first, and the photocatalytic behavior and high refractive index of the latter [25-27]. Double layered NPA-bSs were obtained by subsequently coating the NPAS $+\mathrm{SiO}_{2}$ sample with a new layer of a different material, $\mathrm{Al}_{2} \mathrm{O}_{3}$ or $\mathrm{AZO}$ (a mixture of $\mathrm{ZnO}$ and $\mathrm{Al}_{2} \mathrm{O}_{3}$, that is of interest in plasmonic materials [28]), which provoked modifications in both the nanostructured surface material and sample geometrical parameters (pore-size/porosity). The set of analyzed samples allowed us to estimate the effect on the optical parameters of samples with a similar pore-size and porosity, but with different (i) surface materials and (ii) number of coating layers.

\section{Materials and Methods}

\subsection{NPAS Fabrication and Surfaces Coating by Atomic Layer Deposition Method}

The NPAS substrate used for surface modification was obtained by electrochemical anodization of an aluminum disc ( $0.5 \mathrm{~mm}$ thickness and $25 \mathrm{~mm}$ of diameter) of high purity (Al 99.999\%, Goodfellow, UK) using a solution of oxalic acid $(0.3 \mathrm{M})$ under an anodization voltage of $40 \mathrm{~V}$. Prior to the first anodization, the $\mathrm{Al}$ foil was cleaned and electropolished with isopropanol, ethanol, and a 1:3 vol. solution of perchloric acid in ethanol, respectively. Other chemicals $\left(\mathrm{HCl}, \mathrm{CuCl}_{2}, \mathrm{CrO}_{3}\right.$, and $\left.\mathrm{H}_{3} \mathrm{PO}_{4}\right)$ were employed at the end of the electrochemical anodization process for the selective removal of the aluminum substrate and bottom oxide barrier layer. Figure 1a-c show a scheme of the anodization process, being the pore radii and interpore distance of the NPAS, $r_{\mathrm{p}}=d_{\mathrm{p}} / 2=(16 \pm 2) \mathrm{nm}$ and $D_{\text {int }}=(105 \pm 5) \mathrm{nm}$ [12], respectively; whereas a pore length $L_{\mathrm{p}}$ of approximately $60 \mu \mathrm{m}$ was obtained by controlling the duration of the second anodization step, performed under the same anodization conditions as in the first step [18]. 
a)

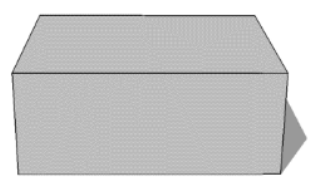

Al foil b)

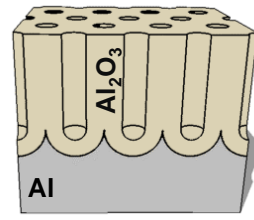

Electrochemical anodization process c)

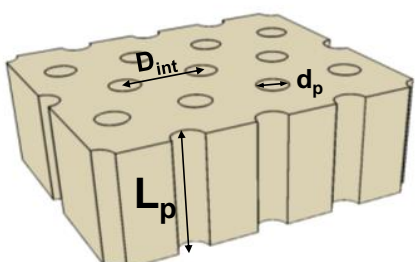

Nanoporous alumina structure d)

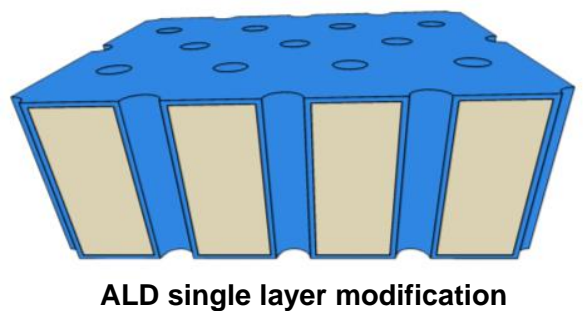

e)

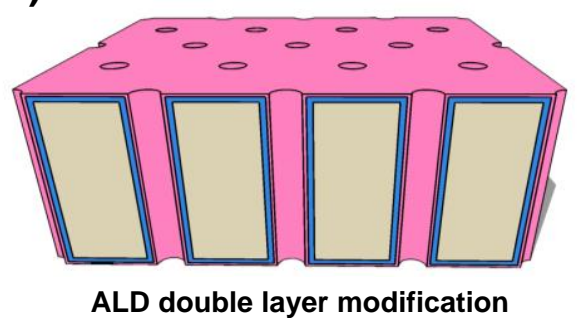

Figure 1. $(\mathbf{a}-\mathbf{c})$ Scheme of the NPAS fabrication and final structure; (d) nanoporous alumina-based structure (NPA-bS) after ideal single layer deposition; (e) NPA-bS after ideal double layer deposition.

ALD coating of the NPAS was performed in a Savannah 100 thermal ALD reactor from Cambridge Nanotech (Waltham, MA, USA), working in exposure mode. High purity argon or nitrogen was employed as the carrier gas, with a typical flow of $50 \mathrm{sccm}$. For the deposition of the different coating layers, at least two precursors were used, the first of them corresponding to the metal precursor, while the other was $\mathrm{H}_{2} \mathrm{O}$, which was employed as an oxidant agent and it is also responsible for the substrate functionalization. In the case of the $\mathrm{SiO}_{2}$ coating deposition, it was also necessary to use an additional oxidant agent, $\mathrm{O}_{3}$, in order to improve the functionalization performed by $\mathrm{H}_{2} \mathrm{O}$ [29]. The cycle configuration in the ALD exposure mode was defined by three different times for each precursor: $t_{1}$ (pulse), $t_{2}$ (exposure), and $t_{3}$ (purge), as shown in Table 1 . Long exposure $\left(t_{2}\right)$ and purge $\left(t_{3}\right)$ times were employed to assure the diffusion of the gaseous precursors along the high aspect ratio pore channels as well as remove the excess reactants and by-products of the ALD process. The use of exposure mode thus enabled the uniform ALD coating of high aspect ratio porous substrates, in contrast to the conventional flow mode (with only pulse and purge steps), which is adequate for flat or low aspect ratio materials. The precursor temperature and pulse time indicated in Table 1 were selected in order to obtain enough vapor pressure and precursor dose in the reaction chamber.

Figure $1 \mathrm{~d}$ shows a scheme of a single layer nanoporous alumina-based structure, and to deposit a coating layer thickness of around $5 \mathrm{~nm}$, the number of coating cycles was adjusted according to the growth rates of the respective oxides. For $\mathrm{TiO}_{2}$ deposition, performed at a substrate temperature of $200{ }^{\circ} \mathrm{C}$, a growth rate of $0.05 \mathrm{~nm} /$ cycle was obtained, which was the reliability of this value for the $\mathrm{NPAS}+\mathrm{TiO}_{2}$ sample already confirmed by the TEM and XPS depth-profile analysis [30,31]. Meanwhile, $\mathrm{SiO}_{2}$ deposition, carried out at $150{ }^{\circ} \mathrm{C}$, yielded a deposition rate of $0.06 \mathrm{~nm} /$ cycle, as previously reported [18,29]. For the double layered samples, schematized in Figure 1e, a $\mathrm{SiO}_{2}$ layer was first deposited on the NPAS as described above; afterwards, the samples were coated with $\mathrm{Al}_{2} \mathrm{O}_{3}$ or $\mathrm{AZO}$ with a layer thickness of about $3.5 \mathrm{~nm}$, which were the corresponding growth rates of the $\mathrm{Al}_{2} \mathrm{O}_{3}$ and AZO layers at $200{ }^{\circ} \mathrm{C}$ that had been previously studied by means of mechanical profilometry and ellipsometry measurements [32]. It is worth clarifying that the AZO layer consisted of a mixture of $\mathrm{Zn}$ and $\mathrm{Al}$ oxides obtained by performing 20 deposition cycles of $\mathrm{ZnO}$, followed by one cycle of $\mathrm{Al}_{2} \mathrm{O}_{3}$, which corresponded to most of the external surface; through this approach, a doping of around $3 \%$ of $\mathrm{Al}$ in the $\mathrm{ZnO}$ layer was obtained [33,34]. According to previous results by SEM image analysis [30], a single layer coverage caused a reduction in pore size $\left(d_{\mathrm{p}}\right)$ and porosity $(\theta)$ of around $20 \%$ and $30 \%$, respectively $\left(d_{\mathrm{p}}=(25 \pm 2) \mathrm{nm}, \theta=6 \%\right)$, while in the case of the double layer, these reductions increased 
by up to around $30 \%$ and $50 \%$, respectively $\left(d_{\mathrm{p}}=(21 \pm 1) \mathrm{nm}, \theta=4 \%\right)$. The supplementary materials show the purities, CAS numbers, and providers of all of the chemicals used (Table S1) as well as the SEM images of the surfaces and cross-sections of some samples and, as an example, the EDX diagram for the NPAS + $\mathrm{TiO}_{2}$ sample (Figure $\mathrm{S} 1$ ).

Table 1. Times and temperatures employed in the ALD processes for the different coating materials, where $t_{1}$ is the precursor pulse time; $t_{2}$ is the exposition time; and $t_{3}$ is the purge lapse. For each material, the times used in the exposure to each precursor are shown by columns, whereas the precursor and substrate temperatures are indicated by lines.

\begin{tabular}{ccccc}
\hline $\begin{array}{c}\text { Material } \\
\text { (Substrate Temperature) }\end{array}$ & $\begin{array}{c}\text { Precursors } \\
\text { (Precursor Temperature) }\end{array}$ & $\boldsymbol{t}_{\mathbf{1}}$ (s) & $\boldsymbol{t}_{\mathbf{2}}$ (s) & $\boldsymbol{t}_{\mathbf{3}}$ (s) \\
\hline \multirow{2}{*}{$\mathrm{ZnO}\left(200^{\circ} \mathrm{C}\right)$} & $\mathrm{H}_{2} \mathrm{O}\left(60^{\circ} \mathrm{C}\right)$ & 0.1 & 90 & 180 \\
& $\left(\mathrm{C}_{2} \mathrm{H}_{5}\right)_{2} \mathrm{Zn}\left(25^{\circ} \mathrm{C}\right)$ & 0.05 & 90 & 180 \\
\hline \multirow{2}{*}{$\mathrm{Al}_{2} \mathrm{O}_{3}\left(200^{\circ} \mathrm{C}\right)$} & $\mathrm{H}_{2} \mathrm{O}\left(60^{\circ} \mathrm{C}\right)$ & 0.1 & 90 & 180 \\
& $\mathrm{Al}_{2}\left(\mathrm{CH}_{3}\right)_{6}\left(25^{\circ} \mathrm{C}\right)$ & 0.05 & 90 & 180 \\
\hline \multirow{2}{*}{$\mathrm{TiO}_{2}\left(200^{\circ} \mathrm{C}\right)$} & $\mathrm{H}_{2} \mathrm{O}\left(60^{\circ} \mathrm{C}\right)$ & 1 & 60 & 120 \\
& $\mathrm{Ti}\left[\mathrm{OCH}_{(}\left(\mathrm{CH}_{3}\right)_{2}\right]_{4}\left(75^{\circ} \mathrm{C}\right)$ & 1 & 60 & 60 \\
\hline \multirow{2}{*}{$\mathrm{SiO}_{2}\left(150^{\circ} \mathrm{C}\right)$} & $\mathrm{H}_{2} \mathrm{O}\left(60^{\circ} \mathrm{C}\right)$ & 1 & 60 & 120 \\
& $\mathrm{O}_{3}\left(25^{\circ} \mathrm{C}\right)$ & 0.1 & 60 & 120 \\
& $\mathrm{H}_{2} \mathrm{~N}\left(\mathrm{CH}_{2}\right)_{3} \mathrm{Si}\left(\mathrm{OC}_{2} \mathrm{H}_{5}\right)_{3}\left(100^{\circ} \mathrm{C}\right)$ & 2 & 60 & 120 \\
\hline
\end{tabular}

\subsection{Chemical Surface Analysis}

The chemical surface characterization of the NPA-bSs samples was performed by analyzing the XPS spectra obtained with a Physical Electronics Spectrometer (PHI 5700, Physical Electronics, Chigasaki, Japan) with $\mathrm{x}$-ray $\mathrm{MgK} \alpha$ radiation as the excitation source $(300 \mathrm{~W}, 15 \mathrm{kV}, 1253.6 \mathrm{eV})$. High-resolution spectra were recorded by a concentric hemispherical analyzer. operating in the constant pass energy mode at $29.35 \mathrm{eV}$, with the diameter of the analyzed area of $720 \mu \mathrm{m}$. Binding energies were determined with respect to the position of the adventitious $\mathrm{C} 1 \mathrm{~s}$ peak at $285.0 \mathrm{eV}$ (accurate $\pm 0.1 \mathrm{eV}$ ), maintaining the residual pressure in the analysis chamber below $5 \times 10^{-7} \mathrm{~Pa}$ during data acquisition. Non-destructive XPS measurements were performed at a given take-off angle $\phi=45^{\circ}$ for the reason of spectrometer optimization. The software package used for data acquisition and analysis was the PHI ACCESS ESCA-V7.0 F. The Shirley-type background was subtracted from the signals, and the recorded spectra were fitted using Gauss-Lorentz curves for a more precise binding energy (BE) determination of the core levels of the different element [35]. The sensitivity factor area for each of the measured spectral regions was considered to determine the atomic concentration percentages of the different elements on the surfaces of the samples.

Although XPS is a surface sensitive technique, a depth profile study can also be performed by means of ion gun etching (a sample-destructive testing process), which analyzes a new sample surface after each ion gun etch cycle. The XPS depth-profile analysis revealed subsurface characteristics that provided information on the nanolayered structures or surface contamination [36]. For this reason, XPS depth-profile analysis for the NPAS $+\mathrm{SiO}_{2}$ sample was carried out by argon sputtering for $10 \mathrm{~min}$ (working conditions: $4 \mathrm{kV}$ and $1.5 \mathrm{~mA}$ ).

\subsection{Spectroscopic Ellipsometry Measurements}

For the characterization of the optical properties of the different NPA-bSs, spectroscopic ellipsometry (SE) measurements (accuracy of 5 decimals) were performed with a commercial spectroscopic ellipsometer (Sopra-Semilab GES 5E, Sopra-Semilab, Budapest, Hungary) for wavelengths covering the visible to near-ultraviolet regions (between 200 and $1000 \mathrm{~nm}$ ) at a fixed incidence angle of $70^{\circ}$. The measurements were directly performed on the NPA-bSs, without employing any other substrate. Winelli software 2.2.0.7 (Sopra-Semilab) was used for the real and 
imaginary parts of the complex refraction index determination (accuracy of 4 decimals) from the experimental parameters.

\subsection{Transmittance Measurements}

Transmittance spectra of the NPA-bSs were recorded with a Varian Cary 5000 spectrophotometer (Agilent Technologies, Santa Clara, CA, USA) provided with an integrating sphere of Spectralon for a wavelength interval of 250-1500 nm. Transmittance spectra were measured for NPA-bSs, and no other substrate was used for these measurements.

\section{Results and Discussion}

\subsection{Chemical Characterization of the Nanoporous Alumina-Based Structures}

The XPS technique was used for chemical surface characterization of the alumina-based nanoporous structures to obtain information on the homogeneity of the coating layer. Atomic concentration percentages (A.C.\%) of the different elements present on the surfaces of the studied NPA-bSs were determined by analyzing the XPS spectra, taking into account the area of the corresponding signals [37]. Table 2 only shows the A.C.\% obtained for the characteristic elements of each sample $(\mathrm{O}$ and $\mathrm{Si}, \mathrm{Ti}, \mathrm{Al}$, and $\mathrm{Zn}$, depending on the sample, and consequently a $100 \%$ value was not reached); moreover, the presence of other non-characteristic coating layer material elements or impurities $(\mathrm{P}, \mathrm{Cl} \ldots$ with A.C. $\%<0.5$ as well as nitrogen and carbon with higher percentages) associated with sample processing or environmental contamination were also detected, as has already been reported for commercial and experimental inorganic and polymeric samples by different authors [37-39]. Results collected in Table 2 showed rather good coverage of the alumina support by the $\mathrm{TiO}_{2}$ and the $\mathrm{SiO}_{2}$ single layers according to the low $\mathrm{Al} \%$ obtained, but the high content of carbonaceous species from contamination hindered the corroboration of correct material stoichiometry; in fact, the high carbon percentage detected on the sample surfaces is discussed in the next paragraph. For example, the core level spectra of $\mathrm{Ti}, \mathrm{O}, \mathrm{Al}$, and $\mathrm{C}$ for the $\mathrm{NPAS}+\mathrm{TiO}_{2}$ sample are given as supplementary information (Figure S2), where a clear and well defined peak at $285.0 \mathrm{eV}$ (Figure S2d) associated with aliphatic carbon as well as a shoulder at $288.5 \mathrm{eV}$ could be observed.

Table 2. Atomic concentration percentages (A.C.\%) of the characteristic elements of each alumina-based nanoporous structure *.

\begin{tabular}{cccccc}
\hline Sample & $\mathbf{O}(\%)$ & $\mathbf{A l}(\%)$ & $\mathbf{S i}(\%)$ & $\mathbf{T i}(\%)$ & $\mathbf{Z n}(\mathbf{\%})$ \\
\hline $\mathrm{NPAS}+\mathrm{SiO}_{2}$ & 28.8 & 2.1 & 4.0 & - & - \\
$\mathrm{NPAS}+\mathrm{TiO}_{2}$ & 52.2 & 1.5 & - & 21.4 & - \\
$\mathrm{NPAS}+\mathrm{SiO}_{2}+\mathrm{Al}_{2} \mathrm{O}_{3}$ & 29.1 & 6.5 & 0.3 & - & - \\
$\mathrm{NPAS}+\mathrm{SiO}_{2}+\mathrm{AZO}$ & 30.5 & 9.0 & 2.3 & - & 0.7 \\
\hline
\end{tabular}

${ }^{*}$ Carbon, nitrogen, and other non-characteristic elements $(\mathrm{P}, \mathrm{Cl} \ldots$ ) found on the surfaces of the analyzed samples are not indicated.

To determine the effect of contamination on the coating layers, destructive depth-profile analysis for the NPAS $+\mathrm{SiO}_{2}$ sample was also performed, and Figure 2a shows the variation with the $\mathrm{Ar}$ sputtering time of the atomic concentration percentages of its characteristic elements, silicon, aluminum, and oxygen, but the changes in the carbon percentage, which is an element commonly observed and associated with contamination (both environmental and manufacture contamination), are also indicated. This point was confirmed by the significant reduction in the C\% (around 60\%) after approximately $0.5 \mathrm{~min}$ Ar sputtering, which caused a notable increase in the other three elements, $\mathrm{Al} \%, \mathrm{Si} \%$, and $\mathrm{O} \%$ in part (ii), confirming the surface contamination contribution. Subsequently, a reduction in $\mathrm{Si} \%$ was detected once the external $\mathrm{SiO}_{2}$-cover layer was eliminated, and a practically constant value associated with nanopore coverage was finally reached, while the higher constant value determined for the $\mathrm{Al} \%$ was due to the solid body of the NPASs, as it is schematically indicated in 
Figure $2 \mathrm{~b}$. In the case of carbon $\%$, the practically constant residual value can be attributed to impurities related to the chemicals used for surface coverage by the ALD method. On the other hand, due to the inhomogeneity of the coating layer, direct sputtering time-depth correlation was not possible since the applied factor depends on the specific material, although an analyzed depth of around $25-30 \mathrm{~nm}$ was assumed. From these results, a thickness of around 5-7 nm for the superficial silica layer in the $\mathrm{NPAS}+\mathrm{SiO}_{2}$ sample was estimated, which is in agreement with previous results obtained for the $\mathrm{NPAS}+\mathrm{TiO}_{2}$ sample [30]. Moreover, the values in Figure 2a also show that once the environmental contamination layer was eliminated (part (i)), the stoichiometry ratios for the bulk NPA-bS (part (ii)) characteristic elements matched adequately.
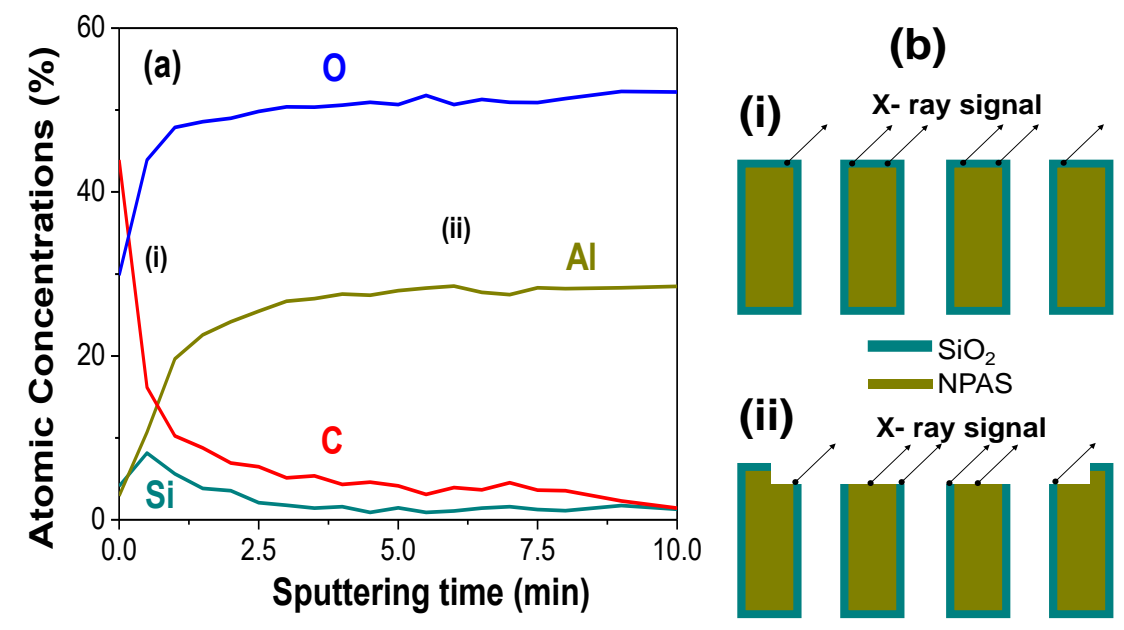

Figure 2. (a) Variation of the atomic concentration percentages of silicon, aluminum, carbon, and oxygen with the XPS sputtering time for the NPAS $+\mathrm{SiO}_{2}$ sample; (b) schemes of the XPS depth-profile analysis for: (i) the external surface, and (ii) during the argon etching process for the $\mathrm{NPAS}+\mathrm{SiO}_{2} \mathrm{sample}$

\subsection{Optical Characterization of the Nanoporous Alumina-Based Structures}

The effect of various coating materials and layers on the transmittance characteristics of the nanoporous alumina support structure was investigated by comparing the corresponding transmittance curves. Figure 3 shows the variation of light transmittance \% with the wavelength for the different samples, where the similarity of the curve shape and the practical constancy of the transmittance value for wavelengths higher than $500 \mathrm{~nm}$ for the $\mathrm{NPAS}+\mathrm{SiO}_{2}, \mathrm{NPAS}+\mathrm{TiO}_{2}$, and $\mathrm{NPAS}+\mathrm{SiO}_{2}+\mathrm{Al}_{2} \mathrm{O}_{3}$ samples could be observed, but this value increased to around $800 \mathrm{~nm}$ in the case of the NPAS $+\mathrm{SiO}_{2}+\mathrm{AZO}$ sample. Taking into account the similar values of geometrical parameters presented by the NPAS $+\mathrm{SiO}_{2}$ and NPAS $+\mathrm{TiO}_{2}$ samples at one side, or the NPAS $+\mathrm{SiO}_{2}+$ $\mathrm{Al}_{2} \mathrm{O}_{3}$ and NPAS $+\mathrm{SiO}_{2}+\mathrm{AZO}$ samples on the other side, differences in the transmittance percentages must be caused by the coating layer material. In this context, a comparison of the transmittance curves for the NPAS $+\mathrm{TiO}_{2}$ sample and the NPAS support (grey dashed line) for the whole wavelength range is presented as supplementary information (Figure S3), where the NPAS support values at high wavelengths were practically similar to those obtained for the NPAS $+\mathrm{SiO}_{2}$ sample. Moreover, the inset in Figure 3 showed a magnification of the transmittance results obtained at wavelengths lower than $500 \mathrm{~nm}$ for the analyzed NPAb-Ss and the NPAS support where differences/similarities depending on the coating layer material could be observed.

For comparative reasons, the percentage of transmitted light at two characteristic wavelengths, one in the visible region ( $\lambda=550 \mathrm{~nm}$, which corresponds to the optimum human-eye response) and the other in the infrared region $(\lambda=950 \mathrm{~nm})$ as well as the band gap value (both in $\mathrm{nm}$ and $\mathrm{eV}$ units), which represents the energy threshold for the light adsorption of a given material, are indicated in Table 3. Clear differences can be observed in the values obtained when both $\mathrm{SiO}_{2}$ or $\mathrm{TiO}_{2}$ single-layers, and both double-layer coated nanoporous structures $\left(\mathrm{SiO}_{2}+\mathrm{Al}_{2} \mathrm{O}_{3}\right.$ or $\left.\mathrm{SiO}_{2}+\mathrm{AZO}\right)$ are compared, 
which demonstrate the importance of the coating-layer material for optical applications of NPA-bSs, taking into account the similarity of their geometrical parameters (pore size, porosity, and thickness) of the analyzed samples. On the other hand, differences in transmittance \% between the two selected wavelengths were around $3 \%$ for $\mathrm{NPAS}+\mathrm{SiO}_{2}, \mathrm{NPAS}+\mathrm{TiO}_{2}$ and $\mathrm{NPAS}+\mathrm{SiO}_{2}+\mathrm{Al}_{2} \mathrm{O}_{3}$, but this difference increased up to $13 \%$ in the case of the $\mathrm{NPAS}+\mathrm{SiO}_{2}+\mathrm{AZO}$ sample. It should be indicated that a rather similar transmittance percentage (around 85\%) was obtained for the AZO films deposited on quartz glasses ( $\mathrm{Al}$ content between $0.9 \%$ and $4.4 \%$ ) [40]. Moreover, differences in band-gap values for the studied nanostructures depending on the coating layer material could also be observed in Table 3 , which supports the possible election of a particular material for a specific optical application. Taking into account the referenced band-gap values for the pure ceramic oxides of the coating layers [41]: $\mathrm{SiO}_{2}(155-119 \mathrm{~nm}), \mathrm{TiO}_{2}(413-330 \mathrm{~nm}), \mathrm{Al}_{2} \mathrm{O}_{3}(177-133 \mathrm{~nm})$, and $\mathrm{AZO}$ (379-346 nm for the Al content varying between 0 and $4.4 \%$ ), our results showed rather good similarity for the $\mathrm{NPAS}+\mathrm{TiO}_{2}$ and $\mathrm{NPAS}+\mathrm{SiO}_{2}+\mathrm{AZO}$ samples, but differences seemed to exist when the other samples were considered, which might be related to the surface contamination already detected by the XPS measurements.

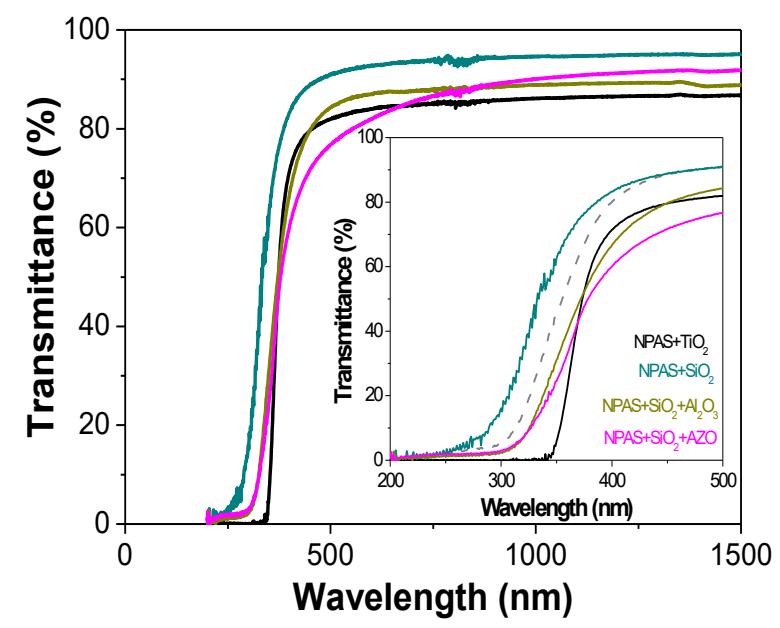

Figure 3. Variation of light transmittance with wavelength for: $\mathrm{NPAS}+\mathrm{SiO}_{2}$ (cyan); $\mathrm{NPAS}+\mathrm{TiO}_{2}$ (black); NPAS $+\mathrm{SiO}_{2}+\mathrm{Al}_{2} \mathrm{O}_{3}$ (yellow); $\mathrm{NPAS}+\mathrm{SiO}_{2}+\mathrm{AZO}$ (pink) samples; and the NPAS support (grey dashed line). The inset shows the transmittance \% for the lowest wavelength interval (200-500 nm).

Table 3. Values of light transmitted \% at two wavelengths (550 and $950 \mathrm{~nm}$ ) and the band gap for the studied nanoporous alumina based structures.

\begin{tabular}{cccc}
\hline Sample & $\boldsymbol{T} \mathbf{( \% )}$ at $\mathbf{5 5 0} \mathbf{~} \mathbf{m}$ & $\boldsymbol{T} \mathbf{( \% )}$ at $\mathbf{9 5 0} \mathbf{~ n m}$ & Band Gap (nm/eV) \\
\hline $\mathrm{NPAS}+\mathrm{SiO}_{2}$ & 92.0 & 94.6 & $281.8 / 4.40$ \\
$\mathrm{NPAS}+\mathrm{TiO}_{2}$ & 83.3 & 86.1 & $346.8 / 3.58$ \\
$\mathrm{NPAS}+\mathrm{SiO}_{2}+\mathrm{Al}_{2} \mathrm{O}_{3}$ & 86.4 & 89.1 & $308.8 / 4.02$ \\
$\mathrm{NPAS}+\mathrm{SiO}_{2}+\mathrm{AZO}$ & 78.0 & 90.1 & $312.5 / 3.87$ \\
\hline
\end{tabular}

On the other hand, different characteristic material parameters such as the refractive index, the extinction coefficient, and the real and imaginary parts of the complex dielectric constant $(\varepsilon)$ can be determined by the SE technique. SE is a nondestructive and noninvasive technique that allows changes to be measured in the light polarization due to its reflection from a solid structure as is schematically shown in Figure 4a for a single structure and in Figure $4 \mathrm{~b}$ for the layer coverage of a support. The interactions of polarized light with a sample include the parallel $(p)$ and normal (n) components of the electric field for both incident $(i)$ and reflected $(r)$ light. [42]. Ellipsometric 
measurements consider two main parameter: angles $\Psi$ and $\Delta$, which are related with differential changes in light amplitude and phase through the following expression [42]:

$$
\tan (\Psi) \mathrm{e}^{i \Delta}=r_{p} / r_{s}
$$

where $\tan (\Psi)$ is the amplitude ratio upon reflection and $\Delta=\delta_{p}-\delta_{s}$ is the phase shift difference, where $r_{p}$ and $r_{s}$ are the amount (intensity) of reflected light polarized in the perpendicular and parallel planes with respect to the plane of incidence, respectively.

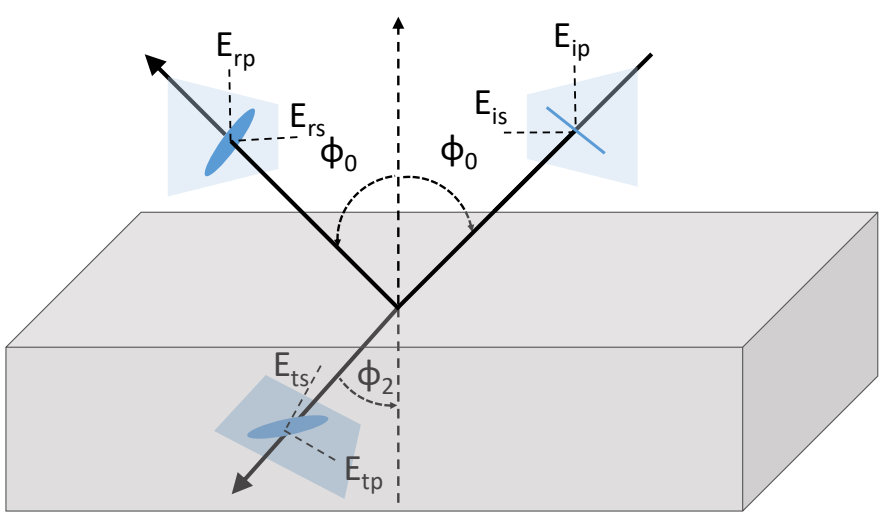

(a)

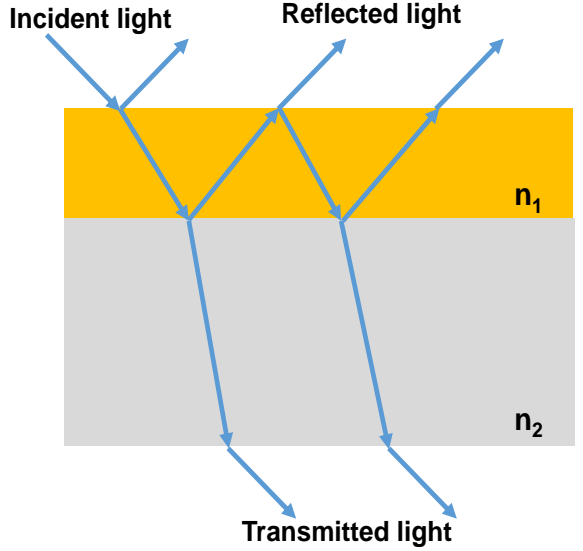

(b)

Figure 4. Scheme of spectroscopy ellipsometry measurement for: (a) the homogeneous sample; (b) the monolayer surface coated sample.

Figure 5 shows a comparison of the wavelength dependence of measured parameters, $\cos (\Delta)$ and $\tan (\Psi)$ as well as the determined $\Delta$ and $\Psi$ angles, where differences dependent on the single-layer or double-layer coated samples as well as the material layers can be observed. Oscillatory values for $\cos (\Delta)$ were similar to those reported in the literature for anodized nanoporous aluminum oxide films [43], where oscillation separation or maximum-minimum height in the case of $\tan (\Psi)$ representation seems to be related to the time employed during electrochemical etching, which is related to the pore-size/porosity of the sample. Figure $5 \mathrm{c}$,d show the variation of $\Psi$ and $\Delta$ with the wavelength for single and double double-layer coated samples, showing behavior rather similar to that referenced in the literature [42]. Moreover, the effect of the incident light ellipsometry angle $\Phi_{\mathrm{i}}$ on the $\cos (\Delta)$ and $\tan (\Psi)$ measured parameters as a function of the wavelength can also be considered by comparing the values obtained for the NPA-bS $+\mathrm{TiO}_{2}$ sample at $70^{\circ}$ with those previously determined at $65^{\circ}$ [30], as shown in Figure 5e,f. As observed, increasing $\Phi_{\mathrm{i}}$ hardly modified the shape of the curves, but increased the $\tan (\Psi)$ values.
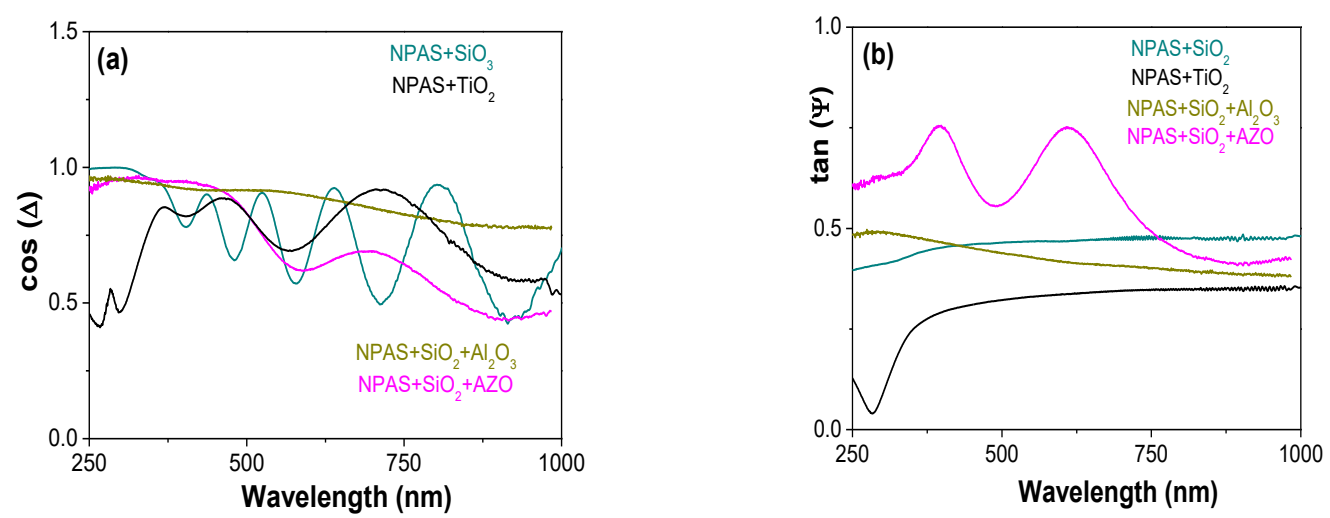

Figure 5. Cont. 

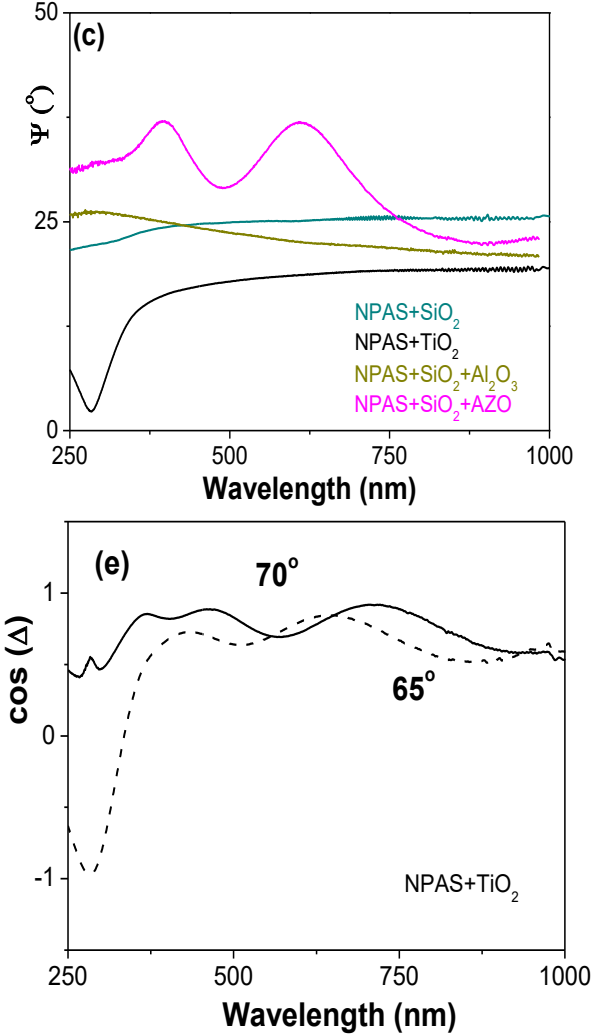
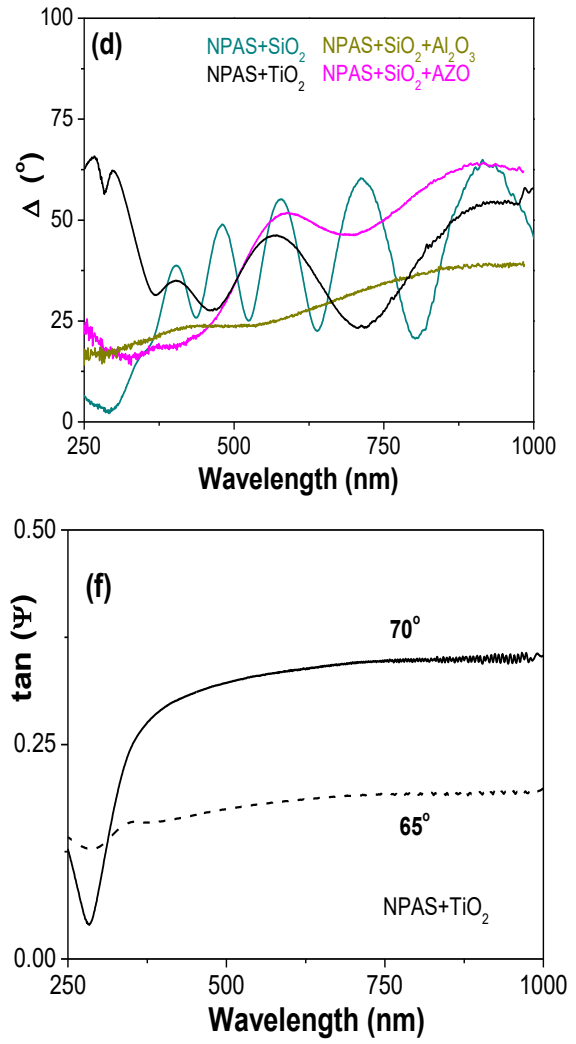

Figure 5. Wavelength dependence of $\cos (\Delta)(\mathbf{a}), \tan (\Psi)(\mathbf{b}), \Delta$ (c) and $\Psi$ (d) for: $\mathrm{NPAS}+\mathrm{SiO}_{2}$ (cyan), $\mathrm{NPAS}+\mathrm{TiO}_{2}$ (black), $\mathrm{NPAS}+\mathrm{SiO}_{2}+\mathrm{Al}_{2} \mathrm{O}_{3}$ (dark yellow), and $\mathrm{NPAS}+\mathrm{SiO}_{2}+\mathrm{AZO}$ (pink) samples Comparison of the measured $\cos (\Delta)(\mathbf{e})$ and $\tan (\Psi)(\mathbf{f})$ values for the $\mathrm{NPAS}+\mathrm{TiO}_{2}$ sample at two different incident angles $\left(65^{\circ}\right.$ and $\left.70^{\circ}\right)$.

As previously indicated, the sample refractive index $(n)$, extinction coefficient $(k)$, and dielectric constant can be determined from SE measurements using the ellipsometer software (Winelli, Sopra-Semilab). Figure 6 shows the dependence of the $n$ and $k$ parameters on the wavelength for the studied nanoporous alumina-based samples, where rather constant values for the refractive index for the wavelength ranging between 375 and $1000 \mathrm{~nm}$ was obtained for the NPAS $+\mathrm{SiO}_{2}$,

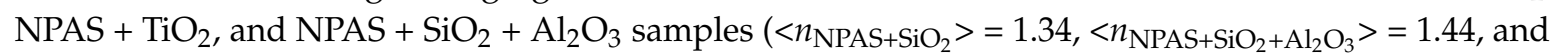
$<n_{\mathrm{NPAS}}+\mathrm{TiO}_{2}>=1.70$ ). These values had rather good agreement with those reported in the literature for pure materials and followed the same tendency [44]; moreover, this parameter seemed to be practically independent of the incident angle according to the values previously obtained for the NPAS $+\mathrm{TiO}_{2}$ sample at $65^{\circ}(n=1.72)$. Disparity in the shape of the $n$ curves is an indication of the differences in the material characteristics, layer thickness, layer interference, or crystallinity [45]. Values of $n$ and $k$ at the two selected wavelengths (550 and $950 \mathrm{~nm}$ ) are indicated in Table 4 for comparative reasons. Moreover, Figure 6 also shows the low wavelength dependence for the $n$ and $k$ parameters obtained for the NAPS $+\mathrm{SiO}_{2}+\mathrm{Al}_{2} \mathrm{O}_{3}$ sample, that is, for the alumina/silica/alumina sandwiched nanoporous structure as well as the practically constant value of the NAPS $+\mathrm{TiO}_{2}$ sample for the range $400-800 \mathrm{~nm}$ as already reported by Taherniya and Raoufi [46], who studied changes in the optical properties of $\mathrm{TiO}_{2}$ thin films obtained by the sol-gel technique associated with film thickness (50, 100 and $150 \mathrm{~nm}$ ), which also affected the porosity (around $40 \%, 28 \%$, and 21\%, respectively). These authors reported an increase of around $12 \%$ in the refraction index and a decrease of $55 \%$ in the extinction coefficient with the increase of film thickness $(\lambda=550 \mathrm{~nm})$ as determined from measurements carried out with samples deposited on a glass substrate, but thickness hardly affected the band gap value (increase of $2.5 \%$ for the whole range); moreover, electrical susceptibility (or the real part of the dielectric constant) also increased $38 \%$ with the film thickness. 


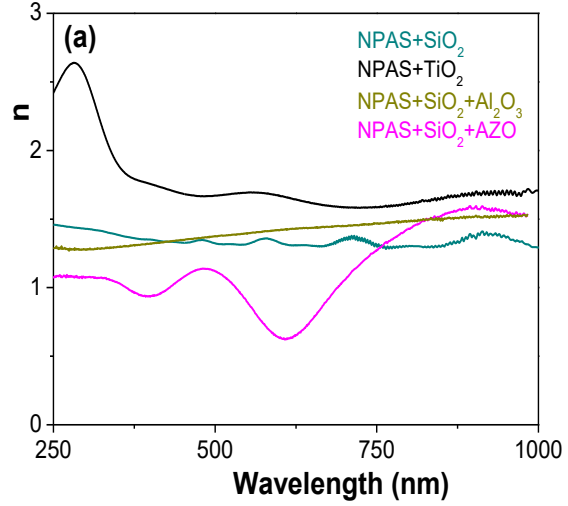

(a)

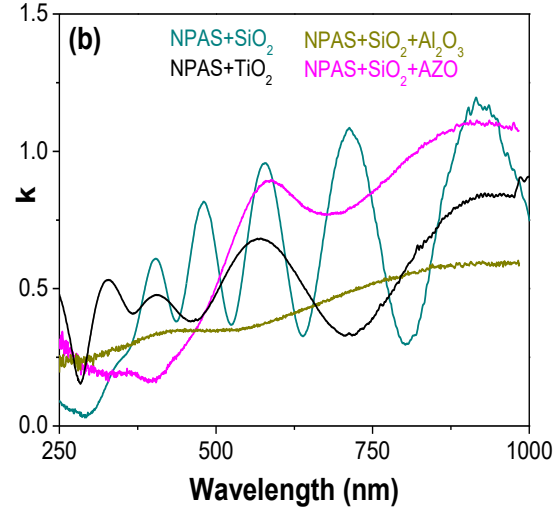

(b)

Figure 6. Wavelength dependence of (a) the refraction index, $n$, and (b) the extinction coefficient, $k$, for the $\mathrm{NPAS}+\mathrm{SiO}_{2}$ (cyan), $\mathrm{NPAS}+\mathrm{TiO}_{2}$ (black), $\mathrm{NPAS}+\mathrm{SiO}_{2}+\mathrm{Al}_{2} \mathrm{O}_{3}$ (dark yellow), and $\mathrm{NPAS}+$ $\mathrm{SiO}_{2}+\mathrm{AZO}$ (pink) samples.

Table 4. Values of the refractive index, $n$, and extinction coefficient, $k$, at two wavelengths (550 and $950 \mathrm{~nm}$ ) for the studied nanoporous alumina based structures.

\begin{tabular}{ccccc}
\hline Sample & $\boldsymbol{n}(\mathbf{a t} \mathbf{5 5 0} \mathbf{n m})$ & $\boldsymbol{k}(\mathbf{a t} \mathbf{5 5 0} \mathbf{n m})$ & $\boldsymbol{n}(\mathbf{a t} \mathbf{9 5 0} \mathbf{n m})$ & $\boldsymbol{k}(\mathbf{a t} \mathbf{9 5 0} \mathbf{~ n m})$ \\
\hline $\mathrm{NPAS}+\mathrm{SiO}_{2}$ & 1.312 & 0.675 & 1.364 & 1.109 \\
$\mathrm{NPAS}+\mathrm{TiO}_{2}$ & 1.693 & 0.663 & 1.704 & 0.837 \\
$\mathrm{NPAS}+\mathrm{SiO}_{2}+\mathrm{Al}_{2} \mathrm{O}_{3}$ & 1.398 & 0.357 & 1.527 & 0.592 \\
$\mathrm{NPAS}+\mathrm{SiO}_{2}+\mathrm{AZO}$ & 0.892 & 0.800 & 1.560 & 1.095 \\
\hline
\end{tabular}

The SE results also provide information on the real and imaginary parts of the dielectric constant taking into account that $\varepsilon=(n+i \cdot k)^{2}$ [42]. Table 5 shows the $\varepsilon_{\mathrm{r}}$ and $\varepsilon_{\mathrm{i}}$ values at the two selected wavelengths, where clear differences among the analyzed samples can be observed. Consequently, both geometrical parameters and material seemed to cause modification in the dielectric constant values of NPA-bSs.

Table 5. Real $\left(\varepsilon_{\mathrm{r}}\right)$ and imaginary $\left(\varepsilon_{\mathrm{i}}\right)$ component values of the dielectric constant at the two wavelengths of 550 and $950 \mathrm{~nm}$ for the studied nanoporous alumina based structures.

\begin{tabular}{ccccc}
\hline Sample & $\varepsilon_{\mathbf{r}}($ at $\mathbf{5 5 0} \mathbf{~ n m})$ & $\varepsilon_{\mathbf{r}}($ at $\mathbf{9 5 0} \mathbf{~ n m})$ & $\varepsilon_{\mathbf{i}}($ at $\mathbf{5 5 0} \mathbf{~ n m})$ & $\varepsilon_{\mathbf{i}}(\mathbf{a t} \mathbf{9 5 0} \mathbf{~ n m})$ \\
\hline $\mathrm{NPAS}+\mathrm{SiO}_{2}$ & 1.282 & 0.630 & 1.779 & 3.025 \\
$\mathrm{NPAS}+\mathrm{TiO}_{2}$ & 2.428 & 2.205 & 2.243 & 2.853 \\
$\mathrm{NPAS}+\mathrm{SiO}_{2}+\mathrm{Al}_{2} \mathrm{O}_{3}$ & 1.826 & 1.982 & 0.997 & 1.807 \\
$\mathrm{NPAS}+\mathrm{SiO}_{2}+\mathrm{AZO}$ & 0.156 & 1.235 & 1.427 & 3.418 \\
\hline
\end{tabular}

\section{Conclusions}

The atomic layer deposition (ALD) technique seems to be an adequate way for the surface modification of nanoporous alumina structures (both external and pore walls) with a high aspect ratio (around 2000) by covering them with one or two layers of different metal oxides $\left(\mathrm{SiO}_{2}, \mathrm{TiO}_{2}, \mathrm{Al}_{2} \mathrm{O}_{3}\right.$, or AZO). Surface coverage was analyzed by XPS measurements at a given take-off angle of $45^{\circ}$ to extract information on the coating layer homogeneity; moreover, XPS depth-profile measurements demonstrated the superficial character of most of the sample impurities associated with fabrication and environmental contamination as well as the presence of coating materials along the pore-walls.

All of the studied samples exhibited high light transmittance (between 86\% and 95\%), but differences were obtained depending on the material coating layer for samples with a similar pore size or porosity, which seems to be an indication of the higher influence of the layer material on the geometrical parameters. As expected, differences in band gap values for the analyzed samples also 
existed, and the following sequence was determined: $\mathrm{NPAS}+\mathrm{SiO}_{2}>\mathrm{NPAS}+\mathrm{SiO}_{2}+\mathrm{AZO} \approx \mathrm{NPAS}+$ $\mathrm{SiO}_{2}+\mathrm{Al}_{2} \mathrm{O}_{3}>\mathrm{NPAS}+\mathrm{SiO}_{2}$. The refraction index, $n$, of the different samples and its dependence on the wavelength in the visible and near IR regions $(250-1000 \mathrm{~nm})$ was determined by spectrometric ellipsometry measurements, and the obtained values showed rather adequate concordance with those referred for the corresponding pure ceramic oxides, although differences in the shape of the curve for samples with similar geometrical parameters were indicative of the repercussion of the particular material and layer characteristics (thickness, crystallinity ... ). Differences in other optical parameters depending on the coating layer material and nanostructure of the sample were also determined, which demonstrated the importance and interest in the appropriate selection of a coating layer material for specific optical applications of alumina-based nanoporous structures.

Supplementary Materials: The following are available online at http:/ / www.mdpi.com/2079-6412/9/1/43/s1, Figure S1: (a) top-view SEM image of the NPAS + $\mathrm{TiO}_{2}$ sample. The inset shows a high magnification SEM image of the parallel aligned nanopores taken at the cross-section: (b) EDX spectrum of (a), indicating the presence of carbon, titanium, oxygen, and aluminum. The Au peaks arise from the sputtered conductive gold layer deposited prior to

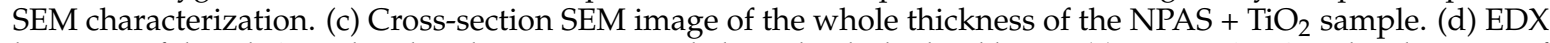
line-scan of the $\mathrm{Al}, \mathrm{O}$, and $\mathrm{Ti}$ distribution measured along the dashed red line in (c). Figure S2: Core level spectra of elements found on the surface of the NPAS + $\mathrm{TiO}_{2}$ sample: (a) Ti 2p, (b) O 1s, (c) Al 2p, and (d) C 1s. Figure S3: Light transmittance (\%) as a function of wavelength for NPAS (grey dotted line) and NPAS $+\mathrm{TiO}_{2}$ (black dense line) samples. Table S1: Chemicals employed in the different NPAM synthesis and ALD deposition steps.

Author Contributions: A.S.G. and V.V. synthesized the NPA support and carried out the ALD-coating process, under the supervision of V.M.P. V.V. performed electron microscopy analysis of the samples. J.B. was responsible of XPS and optical measurements, carried out by M.d.V.M.d.Y. and A.L.C., respectively. V.M.P. and J.B. conceived, designed and discussed the experiments. All authors contributed in co-writing of the manuscript and gave approval to the final revision.

Funding: The financial support is under the Spanish MINECO research project No. MAT2016-76824-C3-3 R.

Acknowledgments: The technical assistance of the SCTs' common research services for the University of Oviedo is acknowledged.

Conflicts of Interest: The authors declare no conflict of interest.

\section{References}

1. Santos, A.; Kumeria, T.; Losic, D. Nanoporous anodic aluminum oxide for chemical sensing and biosensors. Trends Anal. Chem. 2013, 44, 25-38. [CrossRef]

2. McInnes, S.J.; Irani, Y.; Williams, K.A.; Voelcker, N.H. Controlled drug delivery from composites of nanostructured porous silicon and poly (L-lactide). Nanomedicine 2012, 7, 995-1016. [CrossRef] [PubMed]

3. Law, C.S.; Lim, S.Y.; Abell, A.D.; Voelcker, N.H.; Santos, A. Nanoporous anodic alumina photonic crystals for optical chemo- and biosensing: Fundamentals, advances, and perspectives. Nanomaterials 2018, 8, 788. [CrossRef] [PubMed]

4. Masuda, H.; Fukuda, K. Ordered metal nanohole arrays made by a two-step replication of honeycomb structures of anodic alumina. Science 1995, 268, 1466-1468. [CrossRef] [PubMed]

5. Ingham, C.J.; ter Maat, J.; de Vos, W.M. Where bio meets nano: The many uses for nanoporous aluminum oxide in biotechnology. Biotechnol. Adv. 2012, 30, 1089-1099. [CrossRef] [PubMed]

6. Valeev, R.G.; Petukhov, D.I.; Kriventsov, V.V. Structure and optical properties of thin porous anodic alumina films synthesized on a glass surface. Phys. Procedia 2016, 84, 415-420. [CrossRef]

7. Santos, A.; Formentín, P.; Pallarès, J.; Ferré-Borrull, J.; Marsal, L.F. Structural engineering of nanoporous anodic alumina funnels with high aspect ratio. J. Electroanal. Chem. 2011, 655, 73-78. [CrossRef]

8. Loh, J.Y.Y.; Kherani, N. Design of nano-porous multilayer antireflective coatings. Coatings 2017, 7, 134. [CrossRef]

9. Kumeria, T.; Santos, A.; Losic, D. Nanoporous anodic alumina platforms: Engineered surface chemistry and structure for optical sensing applications. Sensors 2014, 14, 11878-11918. [CrossRef]

10. Darder, M.; Aranda, P.; Hernández-Vélez, M.; Manova, E.; Ruiz-Hitzky, E. Structured thin organic active layers and their use in electrochemical biosensors. Thin Solid Films 2006, 495, 321-326. [CrossRef]

11. Schwirn, K.; Lee, W.; Hillebrand, R.; Steinhart, M.; Nielsch, K.; Gösele, U. Self-ordered anodic aluminum oxide formed by $\mathrm{H}_{2} \mathrm{SO}_{4}$ hard anodization. ACS Nano 2008, 2, 302-310. [CrossRef] 
12. Romero, V.; Vega, V.; García, J.; Prida, V.M.; Hernando, B.; Benavente, J. Ionic transport across tailored nanoporous anodic alumina membranes. J. Colloids Interface Sci. 2012, 376, 40-46. [CrossRef] [PubMed]

13. Losic, D.; Velleman, L.; Kant, K.; Kumeria, T.; Gulati, K.; Shapter, J.G.; Beattie, D.A.; Simovic, S. Self-ordering electrochemistry: A simple approach for engineering nanopore and nanotube arrays for emerging applications. Aust. J. Chem. 2011, 64, 294-301. [CrossRef]

14. Lee, W.; Park, S.J. Porous anodic aluminum oxide: Anodization and templated synthesis of functional nanostructures. Chem. Rev. 2014, 114, 7487-7556. [CrossRef] [PubMed]

15. Losic, D.; Simovic, S. Self-ordered nanopore and nanotube platforms for drug delivery applications. Exp. Opin. Drug Deliv. 2009, 6, 1363-1381. [CrossRef] [PubMed]

16. Porta-i-Batalla, M.; Xifré-Pérez, E.; Eckstein, C.; Ferré-Borrull, J.; Marsal, L.F. 3D nanoporous anodic alumina structures for sustained drug release. Nanomaterials 2017, 7, 227. [CrossRef] [PubMed]

17. Velleman, L.; Triani, G.; Evans, P.J.; Shapter, J.G.; Losic, D. Structural and chemical modification of porous alumina membranes. Microporous Mesoporous Mater. 2009, 126, 87-94. [CrossRef]

18. Romero, V.; Vega, V.; García, J.; Zierold, R.; Nielsch, K.; Prida, V.M.; Hernando, B.; Benavente, J. Changes in morphology and ionic transport induced by $\mathrm{ALD} \mathrm{SiO}_{2}$ coating of nanoporous alumina membranes. ACS Appl. Mater. Interfaces 2013, 5, 3556-3564. [CrossRef]

19. Ivanova, T.V.; Homola, T.; Bryukvin, A.; Cameron, D.C. Catalytic performance of $\mathrm{Ag}_{2} \mathrm{O}$ and $\mathrm{Ag}$ doped $\mathrm{CeO}_{2}$ prepared by atomic layer deposition for diesel soot oxidation. Coatings 2018, 8, 237. [CrossRef]

20. Elam, J.W.; Routkevitch, D.; Mardilovich, P.P.; George, S.M. Conformal coating on ultrahigh-aspect-ratio nanopores of anodic alumina by atomic layer deposition. Chem. Mater. 2003, 15, 3507-3517. [CrossRef]

21. Vega, V.; Gelde, L.; González, A.S.; Prida, V.M.; Hernando, B.; Benavente, J. Diffusive transport through surface functionalized nanoporous alumina membranes by atomic layer deposition of metal oxides. J. Ind. Eng. Chem. 2017, 52, 66-72. [CrossRef]

22. Weber, M.; Julbe, A.; Ayral, A.; Miele, P.; Bechelany, M. Atomic layer deposition for membranes: Basics, challenges, and opportunities. Chem. Mater. 2018, 30, 7368-7390. [CrossRef]

23. Moghadam, H.; Samimi, A.; Behzadmehr, A. Effect of nanoporous anodic aluminum oxide (AAO) characteristics on solar absorptivity. Transp. Phenom. Nano Micro Scales 2013, 1, 110-116. [CrossRef]

24. Thompson, D.W.; Snyder, P.G.; Castro, L.; Yan, L.; Kaipa, P.; Woollam, J.A. Optical characterization of porous alumina from vacuum ultraviolet to midinfrared. J. Appl. Phys. 2005, 97, 113511. [CrossRef]

25. Lu, J.; Liong, M.; Li, Z.; Zink, J.I.; Tamanoi, F. Biocompatibility, biodistribution, and drug-delivery efficiency of mesoporous silica nanoparticles for cancer therapy in animals. Small 2010, 6, 1794-1805. [CrossRef] [PubMed]

26. Finch, D.S.; Oreskovic, T.; Ramadurai, K.; Herrmann, C.F.; George, S.M.; Mahajan, R.L. Biocompatibility of atomic layer-deposited alumina thin films. J. Biomed. Mater. Res. A 2008, 87A, 100-106. [CrossRef] [PubMed]

27. Ruiz-Hernández, E.; Baeza, A.; Vallet-Regí, M. Smart drug delivery through DNA/magnetic nanoparticle gates. ACS Nano 2011, 5, 1259-1266. [CrossRef]

28. Pradhan, A.K.; Mundle, R.M.; Santiago, K.; Skuza, J.R.; Xiao, B.; Song, K.D.; Bahoura, M.; Cheaito, R.; Hopins, P.E. Extreme tunability in aluminum doped Zinc Oxide plasmonic materials for near-infrared applications. Sci. Rep. 2014, 4, 6415. [CrossRef]

29. Bachmann, J.; Zierold, R.; Chong, Y.T.; Hauert, R.; Sturm, C.; Schmidt-Grund, R.; Rheinländer, B.; Grundmann, M.; Gösele, U.; Nielsch, K. A practical, self-catalytic, atomic layer deposition of silicon dioxide. Angew. Chem. Int. Ed. 2008, 47, 6177-6179. [CrossRef]

30. Gelde, L.; Cuevas, A.L.; Martínez de Yuso, M.D.V.; Benavente, J.; Vega, V.; González, A.S.; Prida, V.M.; Hernando, B. Influence of $\mathrm{TiO}_{2}$-coating layer on nanoporous alumina membranes by ALD technique. Coatings 2018, 8, 60. [CrossRef]

31. Meng, X.; Banis, M.N.; Geng, D.; Li, X.; Zhang, Y.; Li, R.; Abou-Rachidb, H.; Sun, X. Controllable atomic layer deposition of one-dimensional nanotubular $\mathrm{TiO}_{2}$. Appl. Surf. Sci. 2013, 266, 132-140. [CrossRef]

32. Iglesias, L.; Vega, V.; García, J.; Hernando, B.; Prida, V.M. Development of electrostatic supercapacitors by atomic layer deposition on nanoporous anodic aluminum oxides for energy harvesting applications. Front. Phys. 2005, 3, 12. [CrossRef]

33. Banerjee, P.; Lee, W.-J.; Bae, K.-R.; Lee, S.B.; Rubloff, G.W. Structural, electrical, and optical properties of atomic layer deposition Al-doped ZnO films. J. Appl. Phys. 2010, 108, 043504. [CrossRef] 
34. Fernández-Menéndez, L.J.; González, A.S.; Vega, V.; Prida, V.M. Electrostatic supercapacitors by atomic layer deposition on nanoporous anodic alumina templates for environmentally sustainable energy storage. Coatings 2018, 8, 403. [CrossRef]

35. Moulder, J.F.; Stickle, W.F.; Sobol, P.E.; Bomben, K.D. Handbook of X-ray Photoelectron Spectroscopy; Chastain, J., Ed.; Perkin-Elmer Corporation: Waltham, MA, USA, 1992.

36. Cumpson, P.J. Angle-resolved XPS and AES: Depth-resolution limits and a general comparison of properties of depth-profile reconstruction methods. J. Electron. Spectrosc. Relat. Phenom. 1995, 73, 25-52. [CrossRef]

37. Ariza, M.J.; Benavente, J.; Rodríguez-Castellón, E. The capability of X-ray photoelectron spectroscopy in the characterization of membranes: Correlation between surface chemical and transport properties in polymeric membranes. In X-ray Photoelectron Spectroscopy; Wagner, J.M., Ed.; Nova Publishers: Hauppauge, NY, USA, 2009; pp. 257-290.

38. La Flamme, K.E.; Popat, K.C.; Leoni, L.; Markiewicz, E.; LaTempa, T.J.; Roman, B.B.; Grimes, C.A.; Desai, T.A. Biocompatibility of nanoporous alumina membranes for immunoisolation. Biomaterials 2007, 28, 2638-2645. [CrossRef] [PubMed]

39. Cheow, P.-S.; Liu, L.; Toh, C.-S. Grafting of nanoporous alumina membranes and films with organic acids. Surf. Interface Anal. 2007, 39, 601-610. [CrossRef]

40. Hou, Q.; Meng, F.; Sun, J. Electrical and optical properties of Al-doped $\mathrm{ZnO}$ and $\mathrm{ZnAl}_{2} \mathrm{O}_{4}$ films prepared by atomic layer deposition. Nanoscale Res. Lett. 2013, 8, 144. [CrossRef] [PubMed]

41. Strehlow, W.H.; Cook, E.L. Compilation of energy band gaps in elemental and binary compound semiconductors and insulators. J. Phys. Chem. Ref. Data 1973, 2, 163-199. [CrossRef]

42. Losurdo, M.; Begmair, M.; Bruno, G.; Cattelan, D.; Cobet, C.; De Martina, A.; Fleischer, K.; Dohcevic-Mitrovic, Z.; Esser, N.; Galliet, M.; et al. Spectroscopic ellipsometry and polarimetry for materials and systems analysis at the nanoscale: State-of-art, potential, and perspectives. J. Nanopart. Res. 2009, 11, 1521-1554. [CrossRef] [PubMed]

43. Gâlcä, A.C.; Kooij, E.S.; Wormeester, H.; Salm, C.; Leca, V.; Rector, J.H.; Poelsema, B. Structural and optical characterizations of porous anodic aluminium oxide. J. Appl. Phys. 2003, 94, 4296-4305. [CrossRef]

44. RefractiveIndex.INFO. Available online: https:// refractiveindex.info/ (accessed on 14 January 2019).

45. Tompkins, G.; Hilfiker, J.N. Spectroscopic Ellipsometry: Practical Application to Thin Film Characterization, 1st ed.; Momentum Press: New York, NY, USA, 2016; pp. 57-70.

46. Taherniya, A.; Roufi, D. Thickness dependence on structural, optical and morphological properties of sol-gel derived $\mathrm{TiO}_{2}$ thin film. Mater. Res. Express 2019, 6, 016417. [CrossRef] 